\title{
Bioseguridad en odontología ante COVID-19: revisión de aporte a estudiantes y profesionales
}

\author{
Biosafety in dentistry against COVID-19: review of contribution \\ to students and professionals
}

Janneth Estefanía Barreto Paredes ${ }^{1 a}$

Josué David Condolo Macas ${ }^{1 a}$

Jessenia Alejandra Fernández Guamán ${ }^{1 a}$

Susana Patricia González Eras ${ }^{2 b}$

Liliana Elizabeth Picoita Castro ${ }^{2 b}$
(D) https://orcid.org/0000-0002-8637-8236

(D) https://orcid.org/0000-0001-7595-1896

(3ttps://orcid.org/0000-0001-7358-6901

https://orcid.org/0000-0001-9519-1150

https://orcid.org/ 0000-0001-7232-2568

Correspondencia: janneth.barreto@unl.edu.ec

\section{Resumen}

La COVID-19 es un virus que ataca a las vías respiratorias y que puede presentar síntomas leves como un resfriado y en algunos casos desencadenar la muerte. Este virus se puede transmitir a través de gotículas de Flugge. En el ámbito odontológico se puede dar por el contacto directo que se presenta con los pacientes por medio de la saliva o por los aerosoles producidos por el instrumental rotatorio. Debido a lo antes mencionado, el profesional debe tener conocimiento sobre las medidas de protección que pueden evitar la propagación del virus en la consulta; para ello se inicia con el triaje, en donde se realizará una serie de preguntas al paciente para ver su condición de salud, si ha presentado algún síntoma que lo haga ser sospechoso de COVID-19 o si ha estado en contacto con alguna persona que ha dado positivo y determinar si su caso requiere una atención inmediata. Para realizar una atención odontológica, el odontólogo debe contar con todas las barreras de protección (guantes, mascarilla, bata, gorro, zapatones, etc.), tener conocimiento de la manera en cómo deben ser colocados y de la misma forma cómo se las debe retirar y, como punto importante, la manera correcta de realizar la desinfección del consultorio y la esterilización del instrumental. También se debe tomar en cuenta la relación que presenta la enfermedad periodontal con el coronavirus, cuáles son las medidas preventivas en estos pacientes y qué recomendaciones se le puede brindar.

Palabras clave: COVID-19, odontología, prevención, bioseguridad

\begin{abstract}
COVID-19 is a virus that attacks the respiratory tract and can present mild symptoms such as a cold and in some cases cause death. This virus can be transmitted through Flugge droplets. In the dental field, transmission can occur by direct contact with patients, through saliva or aerosols produced by the rotary instruments. Therefore, the professional must have knowledge about the protection measures that can prevent the spread of the virus in the consultation. For this, it begins with triage, where a series of questions is asked to the patient to see their health condition, if he has presented any symptoms that make him suspect of COVID-19 or if he has been in contact with someone who has tested positive and determine if his case requires immediate attention. In the case of dental care, the dentist must have all the protective barriers (gloves, mask, gown, cap, shoes, etc.), have knowledge of how they should be placed and how they should be removed, and the correct way to disinfect the dental office and sterilize the instruments. It should also be taken into account the relationship between periodontal disease and coronavirus, what are the preventive measures in these patients and what recommendations can be given.
\end{abstract}

Keywords: COVID-19, dentistry, prevention, biosafety

\footnotetext{
${ }^{1}$ Universidad Nacional de Loja. Loja, Ecuador

a Estudiante

${ }^{\mathrm{b}}$ Docente universitario
} 


\section{Introducción}

Los virus son agentes infecciosos con un tamaño en nanomicras desde 20 y $300 \mathrm{~nm}$, estructurados por un ácido nucleico, DNA o RNA; poseen una organización de estructura simple y responden por un mecanismo particular en una célula viva. ${ }^{1}$

COVID-19, o novel coronavirus, inició en diciembre de 2019 en Wuhan Hubei en China, se proclamó pandemia global el 11 de marzo de 2020. Es una enfermedad respiratoria aguda que presenta cuadros clínicos, desde un resfriado común hasta patologías más graves; la mayor parte de la población contagiada de COVID-19 presenta síntomas leves y se recupera de manera inmediata; sin embargo, al ser una enfermedad nueva con una vacuna en proceso, en algunos pacientes, puede llegar a ser más grave, dando como resultado la muerte del paciente contagiado de COVID-19. ${ }^{2,3}$

El coronavirus se transmite principalmente por las gotículas de Flugge o secreciones nasales; estas se ocasionan cuando un paciente contagiado tose o estornuda al aire libre y está sin protección. La transmisión del coronavirus ocurre durante los métodos que generan aerosoles; por ejemplo, la atención odontológica, por lo que el ambiente de atención dental es fuente de infección, por lo especial de sus tratamientos. La atención dental; por lo general, es cara a cara con los pacientes, con exposición a saliva y sangre. Por la situación sanitaria generada por el coronavirus, se menciona que mientras dure la pandemia se deberá atender tratamientos odontológicos, de preferencia y con prioridad, a pacientes que tengan emergencias y urgencias; todo tratamiento de rutina deberá ser pospuesto. ${ }^{4,5}$

El especialista en odontología está en contacto directo e indirecto con el paciente; por lo general, a una distancia corta (menos de un metro), lo que hace una posible ruta para la replicación del virus con un alto riesgo de contaminación; por lo que, y según lo mencionado, el especialista debe conocer las medidas de protección, para así evitar más contagios en la consulta odontológica. ${ }^{6,7}$

\section{Triaje en pacientes}

El triaje debe llevarse a cabo desde el momento en que llega el paciente a la consulta odontológica; la finalidad es lograr que solamente sean atendidos los pacientes que llegan en forma emergente o por urgencia, pero es importante saber identificar los síntomas por COVID-19, en caso de que un paciente sea sospechoso; así mismo, hay que saber que no todos los individuos infectados por el virus SARS-CoV-2 presentan sintomatología, también pueden ser asintomáticos y, de igual manera, se podrían dar los contagios con otros individuos. ${ }^{8}$

Es recomendable reducir la cantidad de pacientes en una sala de espera; por lo que es importante realizar una comunicación previa por vía telefónica para saber si el paciente requiere atención odontológica inmediata o se podría aplazar. Es muy importante, además, priorizar las atenciones de emergencia y urgencia; es decir, todo aquello que compromete la vida del paciente (hemorragia persistente, traumas graves que involucren huesos craneofaciales) y que requiere una inmediata atención para el alivio del dolor severo o evitar un proceso infeccioso. ${ }^{9}$

Díaz y Sortino ${ }^{10}$ sugieren que para la atención de pacientes, previa a la cita, se realice un interrogatorio a los mismos, en donde se pueda seguir una secuencia que facilite conocer si es que un paciente puede presentar o no COVID-19 con preguntas como las siguientes: 
1. Actualmente ¿Presenta fiebre o la ha presentado en las últimas semanas?

2. ¿Usted ha presentado la pérdida parcial o total del olfato y/o gusto en las últimas semanas?

3. ¿Ha presentado, en las últimas semanas, alguna dificultad respiratoria, como problemas para respirar, tos seca o dolor a nivel de garganta?

4. ¿Ha presentado, en las últimas semanas, problemas digestivos, ya sea diarrea, fatiga o vómitos?

5. ¿Ha presentado, en las últimas semanas, algún tipo de malestar (cefalea, mialgias), debilidad o gran cansancio?

6. ¿Estuvo en contacto directo con algún paciente con sospecha o contagiado con coronavirus?

(Si la respuesta llega a ser afirmativa se debe preguntar si está o ha estado en cuarentena)

7. ¿Se ha realizado exámenes que indiquen que es positivo a COVID-19?

(Si la respuesta llega a ser afirmativa se debe preguntar ¿Hace cuánto tiempo se realizó los exámenes? y ¿Está siguiendo algún tratamiento, actualmente?)

8. ¿Ha sido diagnosticado con COVID-19?

(Si la respuesta llega a ser afirmativa se debe preguntar ¿Hace qué tiempo fue diagnosticado? ¿Siguió la cuarentena?)

Luego de realizar las preguntas, si el paciente da respuestas afirmativas a cualquiera de las interrogantes, esta información nos ayudará a descubrir infección de COVID-19. Si la temperatura corporal está sobre los $37.5^{\circ} \mathrm{C}$, el odontólogo tendría que aplazar la atención dental después de 2 semanas de la presencia de la sintomatología y se derivará al paciente al Centro de Salud más cercano para su diagnóstico, tratamiento y aislamiento social inmediato. ${ }^{11}$

Además, Diaz ${ }^{11}$ indica que, en esta etapa, el paciente tiene que ser categorizado, si este no presenta síntomas que indiquen infección por COVID-19 y necesita ser atendido por una urgencia o emergencia dental se debe dar las respectivas indicaciones de cómo asistir al área odontológica: el uso de mascarilla personal, no asistir con accesorios (joyas, relojes), no acudir a la consulta clínica más que con un acompañante (si el caso es necesario) y solicitar el cepillado dental previo a la cita. Adicional a lo mencionado, como procedimiento habitual, se solicita la firma del consentimiento informado al paciente o al representante legal, en caso de niños, indicando bajo qué estado se encuentra el individuo, según sea el caso. 
Tabla 1

Equipos de protección $n^{7,12}$

\begin{tabular}{|c|c|}
\hline Equipo & Características \\
\hline Gorro & Material desechable \\
\hline Bata & Bata larga con manga larga y puño reforzado \\
\hline Pijama quirúrgico & Tela antifluido \\
\hline Guantes & Deben ser de látex o nitrilo \\
\hline Sobreguante & Plásticos, delgados \\
\hline $\begin{array}{l}\text { Lentes antiempañamiento, Protector } \\
\text { facial }\end{array}$ & $\begin{array}{l}\text { Gafa y pantalla facial de fácil limpieza y desinfección } \\
\text { (transparentes, ligeros y resistentes) }\end{array}$ \\
\hline Cubre zapatos & Material desechable \\
\hline Capucha protectora & Material desechable \\
\hline Mascarilla & $\begin{array}{l}\text { - Las mascarillas quirúrgicas presentan una tasa de } \\
\text { filtración de alrededor del } 80 \% \\
\text { - Las N95 ofrecen una tasa de filtración del } 99 \% \text { de todas } \\
\text { las partículas que miden hasta } 0.6 \mathrm{~mm} \\
\text { Si comparamos información con el diámetro de COVID- } 19 \\
\text { es } 0.12 \mathrm{~mm}\end{array}$ \\
\hline Babero & Preferible material antifluido \\
\hline
\end{tabular}

\section{Desinfección del consultorio}

Es fundamental mantener una adecuada higienización y una correcta ventilación después de atender a cualquier persona, ya que el simple hecho de hablar o respirar es suficiente para que se contaminen las superficies; por esta razón, al realizar la desinfección del consultorio, evitamos que microorganismos que se generan en el medio ambiente originen una contaminación cruzada. Para estos fines, se debe realizar, con frecuencia, una limpieza y desinfección de las áreas compartidas, como son: sala de espera, baño, recepción, además de estructuras que todos pueden usar (manijas de puertas, sillas, electrodomésticos y escritorios); así mismo, se debe retirar de la sala de espera los libros, revistas y material de lectura. Cabe recalcar que toda superficie de contacto debe estar cubierta con una barrera impermeable y esta debe ser limpiada y desinfectada antes de cubrirla nuevamente para el próximo paciente y al final de cada jornada. ${ }^{12,13,9}$

Por otro lado, se debe ventilar el área clínica después de atender a un paciente, con un tiempo de 5 a 10 minutos de ventilación natural es suficiente; si fuera necesario utilizar algún tipo de ventilación artificial, como aire acondicionado o ventiladores (que no es lo ideal), es recomendado hacerlo con ventanas abiertas, pero sin personal o pacientes hasta que se haya terminado de ventilar el área. ${ }^{13}$ 
Para realizar una correcta desinfección de las superficies se debe utilizar el hipoclorito de sodio al $0.1-0.5 \%$ o etanol al $70-90 \%$, ya que estos disminuyen, de gran manera, la infectividad del virus en las superficies dentro del tiempo de exposición de 1 minuto. ${ }^{12,14}$

La Organización Mundial de la Salud sugiere que todas las superficies que se contaminen con secreciones, tanto respiratorias como de otros fluidos corporales, se deben limpiar con una solución desinfectante, la cual debe estar compuesta de hipoclorito de sodio al $0.1 \%$ y, posteriormente, se debe enjuagar con agua limpia después de 10 minutos de que entró en contacto con el cloro. ${ }^{12}$

Es importante que el hipoclorito de sodio al $0.1 \%$ se prepare todos los días, ya que, si lo almacenan para ser usado en otro día, podría no funcionar. Para hacer la solución de hipoclorito de sodio al $0.1 \%$ solo se necesita utilizar 25 mililitros de cloro al $5.25 \%$ en 1 litro de agua destilada. ${ }^{13}$

\section{Esterilización del instrumental}

El área de esterilización es de vital importancia para lograr un éxito en los tratamientos dentales, junto al desempeño del operador en las acciones de desinfección y esterilización. ${ }^{15}$

Gran cantidad de virus logran ser inactivados a altas temperaturas (entre 56 y $65^{\circ} \mathrm{C}$ ), mantenidas durante 1 hora, ya que se logra desnaturalizar las proteínas con las cuales se encuentran formados; en este caso, los procedimientos de esterilización deben ser los habituales, principalmente, usando el calor húmedo (autoclave), siempre y cuando el lavado del instrumental se realice en cubetas de ultrasonido, reemplazando el lavado manual. ${ }^{14,4}$

El instrumental rotatorio de alta velocidad funciona gracias al aire que llega desde el compresor; penetra al interior y luego llega al rotor del instrumental haciendo que gire, cuando se levanta el pie del pedal del equipo se corta el paso del aire, pero, el rotor sigue girando y va aspirando aire contaminado de la zona de trabajo y lo impulsa hacia el interior de la pieza de mano (turbina, micromotor); de esta manera ingresan a la manguera de alimentación del instrumento: saliva, sangre, virutas cortadas, microorganismos; lo cual puede causar una infección cruzada entre pacientes, así se le haya cambiado el instrumental rotatorio. ${ }^{16}$

Las puntas del instrumental rotatorio (fresas, piedras, gomas, discos, etc.) deben esterilizarse por cada uso; en el caso de las piezas de mano se recomienda la utilización de autoclaves tipo $\mathrm{B}$ o $\mathrm{S} .{ }^{16} \mathrm{El}$ resto de instrumental, como el usado en procedimientos clínicos o quirúrgicos, instrumental para el tratamiento de conductos radiculares, bandejas, cajas, deben ser esterilizados, igualmente, por calor húmedo. ${ }^{9}$

\section{Procedimiento clínico}

\section{Colocación del equipo}

Antes de la colocación del equipo de protección se deben tener listas todas las piezas, verificando que no haga falta ningún implemento, y solicitar ayuda para su colocación o hacerlo frente a un espejo. A continuación, se detalla la secuencia para la colocación del equipo de protección, la cual se propone de acuerdo a la revisión de la literatura:

1. Retirar objetos externos de las manos (relojes, pulseras, etc.) y bolsillos. ${ }^{14}$

2. Lavado de manos siguiendo el orden correcto. ${ }^{14}$

3. Colocación de zapatones. ${ }^{14}$

4. Colocación del equipo de protección personal; este debe ser colocado dentro de las instalaciones, no se debe venir con él, ya que puede traer consigo bacterias y virus del exterior. 
5. Colocación de bata quirúrgica; esta debe cubrir desde el cuello hasta las rodillas. ${ }^{17}$

6. Colocación de la mascarilla N-95 cubriendo los bordes de la cara.

7. Colocación de gafas protectoras.

8. Gorro desechable; este debe cubrir el cabello y las orejas en su totalidad. ${ }^{17,18}$

9. Higiene correcta de manos.

10. Colocación de guantes; estos deben cubrir los puños de la bata quirúrgica. ${ }^{18}$

\section{Cómo se retira el equipo}

1. Retiro de zapatones. ${ }^{14}$

2. Retiro de guantes. ${ }^{17}$

- Se toma la parte externa del guante con la mano opuesta, la que aún posee el guante, y se procede a su retiro.

- Mantener el guante retirado en la mano opuesta, la que se encuentra con el guante colocado.

- Deslizar los dedos de la mano sin guante por debajo del otro guante, el que no se ha retirado todavía, a la altura de la muñeca.

- Retire el guante de manera que cubra el primer guante.

3. Lavado de manos.

4. Retirar las gafas protectoras y colocar en un medio desinfectante. ${ }^{18}$

5. Retiro de gorro de manera cuidadosa. ${ }^{14}$

6. Retirar lenta y cuidadosamente la bata, cuidando de no tocar la parte externa.

7. Retirar la mascarilla; haciéndolo desde las orejas.

8. Finalizar con un lavado correcto de manos. ${ }^{18}$

\section{Recomendaciones al paciente}

- Los pacientes deben usar una mascarilla adecuada, antes y después de recibir la atención odontológica, la cual no se retirará hasta que se inicie con el procedimiento odontológico. ${ }^{9}$

- En ciertos casos, donde el paciente no disponga de mascarilla o no cumpla con las medidas de protección, se le proporcionará una mascarilla antes de ingresar al consultorio. ${ }^{19}$

- Los pacientes pueden sumar el uso de un protector facial de manera alternativa. ${ }^{20}$

- Se le pide al paciente que se despoje del reloj, pulsera, anillos, aretes o cualquier accesorio. ${ }^{19}$

- El paciente debe tener el cabello recogido antes de ingresar al consultorio, luego se le proporcionará alcohol en gel y deberá aplicarlo en sus manos durante 20 segundos o deberá realizarse un lavado de manos, en caso de ser posible; en el caso de ser un paciente pediátrico o persona con discapacidad, el tutor o responsable será quien lo ayude con esta actividad. ${ }^{19}$

- El paciente o los acompañantes no rebasarán la línea de marcación en el piso, para mantener el distanciamiento, y tomarán sana distancia en sillas individuales, evitando ocupar sillas bloqueadas. ${ }^{20}$

\section{Profilaxis dental, su importancia ante la COVID-19 y la enfermedad periodontal}

Las enfermedades periodontales (EP) surgen por microorganismos, generando inflamación y daños en los tejidos de los dientes, que pueden estar asociadas a enfermedades como diabetes, hipertensión, asma, enfermedades hepáticas, entre otras. ${ }^{21}$ Surgen debido a la biopelícula bacteriana; ${ }^{22}$ son de carácter infeccioso. Estas pueden denominarse, de acuerdo a la gravedad, como gingivitis o periodontitis. ${ }^{23}$ 


\section{Cuadros periodontales que merecen atención de urgencia}

- Abscesos periodontales. Se da en los tejidos periodontales afectando a pacientes con EP. Es una infección purulenta; su tratamiento consiste en un drenaje, desbridamiento y antibioticoterapia (metronidazol, amoxicilina con ácido clavulánico, azitromicina) durante el tiempo de la etapa aguda (5 a 7 días). Se debe evaluar al paciente y observar su evolución; además de ello, el paciente debe de recordar las instrucciones de higiene bucal con clorhexidina al $0.12 \%$, dos veces al día. ${ }^{23}$

- Enfermedades periodontales necrotizantes. Son patologías infecciosas, entre las cuales se describen a la gingivitis, periodontitis ulceronecrosante y a la estomatitis necrotizante, que causan dolor, y su etiología se asocia al estrés. Su tratamiento consta de antibioticoterapia con metronidazol de $500 \mathrm{mg}$ por 7 días. En la consulta se va a realizar desbridamiento del biofilm y tratamiento diariamente, según la duración de la fase aguda, por medio de instrumentos ultrasónicos o manuales. Evitar los controles mecánicos de biofilm debido a que afecta en la cicatrización de las úlceras. ${ }^{23}$

- Gingivoestomatitis herpética aguda. Se origina por la infección del HSV-1, generando dolor y vesículas que se eliminan y se unen. Su tratamiento consiste en dieta blanda y líquida, hidratación, eliminación del biofilm y enjuagues de clorhexidina al $0.12 \%$. En casos más severos se utiliza antivirales como aciclovir y valaciclovir, ingesta de analgésicos y enjuagues para una mejor comodidad y facilidad de ingerir líquidos. Las consultas telefónicas, en estos casos, son recomendadas con ayuda de fotos, generando un diagnóstico y tratamiento correctos. ${ }^{23}$

\section{Antisépticos en periodoncia}

La forma principal de contagio del SARS-CoV-2 es mediante gotitas de saliva, que se pueden ocasionar al momento de estornudar o toser; sin embargo, se debe tomar en consideración que este virus se puede presentar en la saliva a través de tres mecanismos: por el intercambio de fluidos procedentes de las vías aéreas superiores e inferiores, por el suero sanguíneo liberado al líquido crevicular gingival y por infecciones que se pueden dar en las glándulas salivales, las mismas que se convierten en un reservorio para este virus. ${ }^{23-26}$

Teniendo en cuenta estos mecanismos, es aquí donde los enjuagues bucales podrían ser un factor importante para disminuir la carga bacteriana y viral existente en la cavidad oral a la hora de realizar algún tratamiento dental, ya que es en esta profesión donde se tiene mayor contacto con fluidos corporales como la saliva y sangre, incrementados por el uso de instrumental rotatorio que produce aerosoles como lo es la turbina, micromotor o instrumentos ultrasónicos. ${ }^{23,26,27}$ Además del enjuague bucal que los pacientes pueden usar, y que en varios estudios han demostrado ser eficaces para inhibir la actividad del coronavirus (SARC-CoV-2), está la povidona yodada a una concentración de $1 \%$ y el cloruro de cetilpiridinio que puede ser de $0.05-0.10 \%{ }^{28}$

La povidona yodada es microbicida de amplio espectro contra bacterias, hongos, protozoos y virus, que además es soluble en agua. Es una sustancia que ha demostrado tener propiedades virucidas in vitro contra el SARS-CoV-2. ${ }^{26}$

El cloruro de cetilpiridinio al $0.05 \%$ puede ser una opción adecuada, ya que altera la membrana lipídica de los virus, provocando su ruptura y, por consiguiente, su inactivación. Este enjuague presenta una actividad de 3-5 horas y se debe usar $20 \mathrm{ml}$ durante 1 minuto, 3 veces al día. ${ }^{23,29}$ 


\section{Higiene bucodental}

- Una barrera epitelial gingival sana puede ayudar a evitar que los virus y bacterias patógenas de la cavidad bucal ingresen al torrente sanguíneo. ${ }^{30}$

- El cepillado diario en combinación con el uso de enjuague bucal, principalmente en pacientes con diabetes, podría ayudar a reducir las posibles consecuencias sistémicas de las infecciones por el virus del SARS-CoV-2.30

- Los controles de mantenimiento que se realizan luego de haber culminado con el tratamiento periodontal para minimizar la recurrencia de la enfermedad, debido a la pandemia, quedarán, únicamente, a manos del paciente..$^{23}$

- El cepillo dental debe ser de cerdas suaves, y debido a que son susceptibles a la retención de microorganismos se recomienda utilizar un capuchón que posea una ventilación con el objetivo de evitar su contaminación; usar un vaso para cada cepillo colocándolo de forma vertical y cambiarlo después de algún proceso infeccioso. ${ }^{23}$

- Se recomienda usar un limpiador lingual y no compartir el mismo dentífrico para evitar la contaminación cruzada. ${ }^{23}$

\section{Conclusiones}

- Los profesionales dentro del ámbito de la salud estamos en la obligación de educarnos y educar con las medidas de bioseguridad, dentro y fuera de la consulta odontológica, durante la emergencia sanitaria de COVID-19.

- El odontólogo, como el estudiante, deben tomar todas las medidas para educar a los pacientes, en cuanto a prevención, tratamiento y normas recomendadas, ya que son un grupo de alto riesgo susceptible a infectarse de COVID-19.

- Es importante que mantengamos todas las normas de bioseguridad: seguir utilizando el equipo de protección, tanto del odontólogo como del paciente, mantener las normas de desinfección fuera y dentro del consultorio, conservar la rutina de desinfección y esterilización de todos los equipos e instrumental para minimizar el contagio del virus.

- Seguir motivando a los profesionales del área odontológica a seguir investigando acerca de las normas de bioseguridad y las rutas de contagio en esta emergencia sanitaria.

\section{Referencias}

1. Alarcón D, Ojeda R. Virus: pequeños gigantes que dominan el planeta. Comunicaciones libres. 2018; 69(2).

2. Salud OMdl. OMS. [Online]; 2019. Acceso 10 de Febrerode 2021. Disponible en: HYPERLINK "https:// www.who.int/es/emergencies/diseases/novel-coronavirus-2019" https://www.who.int/es/emergencies/ diseases/novel-coronavirus-2019 .

3. Pública MdS. Ministerio de Salud Pública. [Online].; 2019. Acceso 10 de Febrero de 2021. Disponible en: HYPERLINK "https://www.salud.gob.ec/coronavirus-covid-19/" https://www.salud.gob.ec/coronaviruscovid-19/ .

4. Gómez SG, Prieto RB, Martínez RJ, Melwani S. Protocolo odontológico ante el SARS-CoV-2 (COVID-19) en Atención Primaria. 2020.

5. Barreda E, Cabrera J, Chavarría F, Laparra W, Melgar G, Ordoñes M, et al. Protocolo de bioseguridad odontológica con énfasis en COVID-19. Informa. Guatemala: Colegio de odontólogos de Guatemala, Departamento de Odontología.ISBN.

6. Carreras C, Aranguren J, Baracco B, LLorente A, López J, Montero A. Protocolo de prevencion en la 
clínica dental frente al COVID-19. Informe. coem, Departamento de Odontología.ISBN.

7. Pérez $P$, Bolleto P. Protocolo de bio-seguridad para la atención a pacientes y prevención del COVID-19 en clínicas y consultorios odontológicos. Informe. Paz: Colegio de odontólogos de la Paz, Departamento de Odontología.ISBN.

8. Benoit V, Benedetta A, April B. Los servicios esenciales de salud bucodental en el contexto marco de la COVID-19. Organización Mundial de la Salud. 2020.

9. Ushina P, Barzallo M, Flores I, Sanchez S, Carlos J, Luna D. Protocolo para atención odontológica en emergencias y urgencias odontológicas durantela emergencia sanitaria por COVID-19. MSP. 2020.

10. Diaz MF, Sortino V. Protocolo de bioseguridad para atención en las unidades asistenciales odontológicas. COPBA2. 2020.

11. Diaz Rodriguez M. Manual de Procedimientos de atención odontológica postcovid-19. Odontología Pediátrica. 2020.

12. Rodríguez EAS, Bernal-Pérez JL, Lanata AG, Sánchez C, Rodríguez J, Haidar ZS, et al. COVID-19 y la odontología: una revisión de las recomendaciones y perspectivas para latinoamérica. Odontostomat. 2020.

13. Ensaldo E. COVID-19 y el paciente en el consultorio odontológico. CONAMED. 2020; 25(1).

14. Badanian A. Bioseguridad en odontología en tiempos de pandemia COVID-19. Odontoestomatología. 2021; 22(1).

15. López Palma YA, Almaguer Labrada OR, Fabier Zuleta R. Conocimientos de bioseguridad en tecnólogos activos en la asistencia de urgencias estomatológicas durante la COVID-19. Revista Electrónica Dr. Zoilo E. Marinello Vidaurreta. 2020; 45(4).

16. Verdera S. Protocolo de atención en odontología restauradora ante la emergencia sanitaria COVID-19. Odontoestomatología. 2020; 22(1).

17. Paredes Huamán YY, Villar Tirado DY. Protocolo de bioseguridad en el contexto reinicio de actividades post pandemia COVID-19 en el centro estomatológico UPAGU - cajamarca, 2020. Tesis Doctoral. Cajamarca-Perú: Universidad Privada Antonio Guillermo Urrelo, Facultad De Ciencias De La Salud.

18. Anastacio Balón MM. Acciones del personal de salud del area estomatológica en relación al COVID-19. Tesis de grado. Guayaquil-Ecuador: Universidad de Guayaquil, Facultad de Odontología.

19. Ministerio de Salud Pública del Salvador. Lineamientos técnicos para la atención odontológica posterior a la emergencia por COVID-19. Ministerio de Salud Pública del Salvador. 2020.

20. José Daniel Villegas Maestre LdICFR. Medidas de prevención y control de la COVID-19 en estomatología: "la nueva normalidad". MULTIMED. 2021; 25(2).

21. Pitones-Rubio , Chávez-Cortez EG, Hurtado-Camarena , González-Rascó , Serafín-Higuera. Is periodontal disease a risk factor for severe covid-19 illness? Medical Hypotheses. 2020.

22. Escobar Arregocés FM. COVID-19 su patogenia y relación con enfermedades sistémicas como la enfermedad cardiovascular y la diabetes: ¿Podría la enfermedad periodontal aportar en esta relación? JPAPO. 2020; 4(1).

23. BuenoL. Recomendacionesgeneralesen periodoncia enmomentodepandemia. Odontoestomatología. 2020; 22(1).

24. Cayo-Rojas CF, Baltazar-Sánchez CA. Recomendaciones clínicas odontológicas frente al COVID-19, de acuerdo con la evidencia científica. Revista Habanera de Ciencias Médicas. 2020; 19(2).

25. Sigua-Rodríguez EA, Bernal-Pérez JL, Lanata-Flores AG, Sánchez-Romero C, Rodríguez-Chessa J, Haidar ZSea. COVID-19 y la odontología: una revisión de las recomendaciones y perspectivas para latinoamérica. International journal of odontostomatology. 2020; 14(3).

26. Pedraza Maquera KI, Lévano Villanueva CJU. Efectividad de enjuagues bucales en el tratamiento dental durante la pandemia COVID-19. Revista Odontológica Basadrina. 2020; 4(1). 
27. Matías Santos-López HCF. COVID-19 y el nuevo rol del odontólogo en el equipo de salud. International journal of odontostomatology. 2020; 4(3).

28. Ramírez-Velásquez, Medina-Sotomayor, Morocho Macas. Enfermedad por coronavirus 2019 (COVID-19) y su repercusión en la consulta odontológica: una revisión. Odontol. Sanmarquina. 2020; 23(2).

29. Baghizadeh Fini. What dentists need to know about covid-19. Oral oncology. 2020; 105.

30. Marón SL. COVID-19 y personas mayores, una mirada odontológica. Revisión Sistemática. Revista de la facultad de odontología de la Universidad Nacional de Cuyo. 2020; 14(2).

- Conflicto de intereses: La presente investigación no presenta conflicto de intereses entre los investigadores.

- Fuente de financiamiento: La presente investigación fue financiada por los investigadores. 